\title{
Solubility of $\mathrm{Ru}, \mathrm{Rh}$ and $\mathrm{Ir}$ in spinel and olivine: can the nugget effect be avoided?
}

\author{
IRINA ZHUKOVA ${ }^{1,2}$, HUGH O’NEILL ${ }^{2}$, IAN CAMPBELL ${ }^{2}$,
} MARCO FIORENTINI ${ }^{3}$

${ }^{1}$ State Key Laboratory of Geological Processes and Mineral Resources, China University of Geosciences (Wuhan), 388 Lumo Rd, Hongshan, Wuhan, Hubei 430074, China

${ }^{2}$ Research School of Earth Sciences, The Australian National University, Acton, ACT 2601, Australia

${ }^{3}$ School of Earth Sciences and ARC Centre of Excellence for Core to Crust Fluid Systems, University of Western Australia, Crawley, WA 6009, Australia

In-situ concentrations of compatible platinum group elements (IPGEs) in olivine and chromite are important for understanding of mantle evolution and processes controlling of PGE fractionation. $\mathrm{Ru}$ in $\mathrm{Cr}$-spinel has become an effective exploration indicator and geochemical tracer for coppernickel sulfide-type platinum group element deposits [1,2]. Obtaining reliable solubilities of IPGEs and $\mathrm{Rh}$ in minerals remains challenging because of the presence of abundant micronuggets of platinum group minerals (PGMs).

We report a new approach for the determination of PGE solubilities in olivine and spinel, which avoids the micronugget problem by diffusing the PGE into single crystals [3]. Extrapolation of the diffusion profile to the diffusion interface gives the equilibrium solubility of the PGE in the crystal at the imposed temperature and oxygen fugacity. We performed diffusion experiments for $\mathrm{Rh}, \mathrm{Ru}$ and $\mathrm{Ir}$ into olivine and spinel at 1300 to $1400^{\circ} \mathrm{C}$, over a range of oxygen fugacities from the FMQ buffer to six log units above (FMQ+ 6.6 , in air). For all the experiments, the activities of the main oxide components were controlled using two-phase buffering assemblages.

Experiments demonstrated a strong effect of activity of major components (mineral paragenesis) on the solubilities of the IPGEs and Rh in spinel and olivine at given temperatures and oxigen fugacities. Solubility of IPGEs and $\mathrm{Rh}$ increases as a function of $f \mathrm{O}_{2}$ for both spinel and olivine.

The results of our study provide equilibrium concentrations of IPGEs and $\mathrm{Rh}$ and their diffusivities in spinel and olivine, which reveal the mechanisms of PGEs incorporation in these minerals and helps elucidate their fractionation in magmatic systems.

[1] Locmelis et al. (2018) Ore Geology Reviews 97, 152170. [2] Park et al. (2017) Geochimica Cosmochimica Acta 216, 393-416. [3] Zhukova et al. (2018) Chem Geol 494, 1929. 